\title{
Analisis Peranan Pengendalian Internal Atas Penjualan, Piutang Dan Penerimaan Kas Pada PT. Alfa Scorpii
}

Lili Fizriah ${ }^{1}$, Henny Andriyani Wirananda ${ }^{2}$

1,2Universitas Muslim Nusantara Al-Washliyah

Corresponding Author:@ lilifizriah123@gmail.com

ABSTRACT
This study aims to determine the role of internal control over sales,
accounts receivable and cash receipts at PT. Alfa Scorpii. The data used in
this study is primary data, the subject in this study is PT. Alfa Scorpii.
While the object in this research is internal control. Data collection
techniques were carried out by observation, interviews and
documentation studies. The data analysis technique used is to review the
role of internal control over sales, accounts receivable and cash receipts at
PT. Alfa Scorpii, by collecting data and then studying and reviewing data
based on interviews and documentation, in order to obtain results from
the role of internal control over sales, receivables and cash receipts at PT.
Alfa Scorpii. From the overall research results indicate that the role of
internal control over sales at PT. Alfa Scorpii has been running well
because there is a separation of duties and authority between employees
so as to minimize errors and fraud that might occur in the company. The
role of internal control over receivables at PT. Alfa Scorpii has separated
the parts according to their respective fields, so there is no confusion
when carrying out the tasks assigned by superiors and the company
becomes safe because it can reduce fraud that can be caused by these
employees. Internal control over cash receipts at PT Alfa Scorpii has not
been carried out according to procedures because employees at the
inputting cash receipts section sometimes often cover deposits from other
people due to delaying the recording of cash so as to steal money. The
advice given from the research results is internal control at PT. Alfa
Scorpii has done quite well in the company but there is still control in the
cash receipts section that is still not done well, it is better to warn
employees so that it is carried out properly.
emang

Keywords

Internal Control, Sales, Receivables, Cash Receipts

\section{PENDAHULUAN}

Bagi setiap perusahaan yang memproduksi produk, penjualan merupakan hal yang sangat penting. Dengan adanya penjualan diharapkan adanya keuntungan terhadap produk yang dijual, sehingga perusahaan dalam menjalani kegiatan dapat terus berlangsung. Adanya perkembangan perusahaan, maka jumlah kegiatan dan karyawan perusahaan juga bertambah, sehingga dikendalikan dengan baik. Pengendalian internal merupakan hal yang sangat penting untuk suatu perusahaan, dengan adanya pengendalian internal yang baik, akan mendorong ditetapkannya kebijakan manajemen. 
Manajemen bertanggung jawab untuk mengembangkan dan menyelenggarakan secara efektif struktur pengendalian internal perusahaannya. Inti dari perusahaan yang terkontrol secara efektif berada pada sikap manajemennya. Jika manajemen puncak percaya bahwa kendali adalah penting, orang-orang lain dalam perusahaan itu akan merasakannya dan merespon dengan teliti kendali yang dibuat.

PT. Alfa Scorpii merupakan sebuah perusahaan swasta bergerak dibidang perdagangan yang menjual produk secara tunai dan kredit. PT Alfa Scorpii menjual produk sepeda motor. PT. Alfa Scorpii ini memiliki berbagai produk dengan berbagai merk, bentuk, harga, dan sifat yang berbeda-beda untuk dijual. Dalam menjalankan kegiatan perusahaannya mendatangkan produk melalui prosedur memerlukan pengawasan yang lebih terhadap persediaan.

Semakin berkembang suatu perusahaan maka semakin berkembang pula transaksi yang akan terjadi dan sifat dari transaksi inipun bertambah rumit. Hal ini mengakibatkan timbulnya berbagai ragam permasalahan yang harus dihadapi pimpinan perusahaan. Jika sebelumnya perusahaan dapat dengan mudah menjual produknya secara tunai, Tetapi kini dalam kondisi persaingan yang semakin meningkat memaksa perusahaan merubah bentuk strategi pemasarannya dari pembayaran yang semula hanya tunai menjadi secara kredit. Ini dilakukan upaya untuk meningkatkan penjualan atau mencegah penurunan penjualan. Dengan penjualan meningkat, diharapkan laba semakin meningkat.

Kebijakan dan prosedur yang dibuat oleh perusahaan untuk melakukan transaksi penjualan secara tunai dan kredit tidak dijalankan sesuai persyaratan yang telah ditentukan misalnya pada saat penghantaran sepeda motor kerumah konsumen, konsumen langsung serahkan uang tunai ke sales sehingga sering terjadi penyelewengan uang tidak sampai ke kasir, pada saat penghantaran sepeda motor kerumah konsumen sering juga terjadi sepeda motor tidak sesuai apa yang di inginkan oleh konsumen tersebut contohnya beda warna atau unit lecet, beda tipe sehingga unit tidak jadi diturunkan dirumah konsumen, pada saat penjualan sepeda motor secara kredit tidak menjelaskan kriteria agar disetujui permohonan nya, kriteria yang dimaksud seperti suami/istri wajib mempunyai penghasilan tetap perbulan yang dibuktikan dengan slip gaji asli dari perusahaan tempat mereka bekerja, wajib ada alamat dan nomor telepon, konsumen harus bekerja minimal 1 tahun, jadi kalau tidak memenuhi kriteria tersebut bisa saja konsumen pindah rumah dan membawa lari sepeda motor kapan mereka mau saja

Perusahaan membeli spare part yang sulit lakunya karena jarang digunakan konsumen, membuat stok spare part bertumpuk di showroom yang 
mengakibatkan tertanamnya modal perusahaan dalam waktu yang lama sehingga tidak dapat dengan cepat untuk memutar modal tersebut, contoh spare part nya tali gas, tali kopling, list body, dan tali vibelt.

Masih terdapat dalam lingkungan pengendalian yang hanya mementingkan kebutuhan kerjanya tanpa mempertimbangkan kendalakendala yang dihadapi pada kelompok atau divisi lain pada perusahaan dan beberapa pekerjaan masih dikerjakan oleh beberapa orang. Lemahnya penentuan risiko terhadap pengendalian internal piutang yang selama periode penelitian dapat dideskripsikan setiap tahunnya angka piutang macet makin bertambah. Ditemukan bahwa manager dan supervisor tidak melakukan pemeriksaan secara rutin terhadap map aplikasi sehingga menimbulkan adanya persimpangan. Selain itu juga ditemukan bahwa administrasi collection tidak melakukan pemeriksaan serah terima kwitansi kepada collector pagi dan sore secara rutin, sehingga menyebabkan adanya lapping.

Informasi dan komunikasi disini ditemukan kurangnya interaksi antara atasan dan para staff yang belum terjalin dengan baik. Selain itu, dalam sistem pemantauan, ditemukan juga bahwa surveyor dalam mensurvei konsumen tidak melihat kondisi konsumen apakah layak diberikan kreditan dalam proses transaksi penjualan sehingga terjadi penyimpangan pada saat pembayaran.

Berdasarkan penjelasan diatas, penulis tertarik untuk meneliti dengan judul "Analisis Peranan Pengendalian Internal Atas Penjualan, Piutang dan Penerimaan Kas Pada PT. Alfa Scorpii."

\section{METODE PENELITIAN}

Desain penelitian berfungsi untuk membantu pelaksanaan penelitian agar dapat berjalan dengan baik. Desain penelitian yang dilakukan pada penelitian ini adalah metode deskriptif kualitatif.

Menurut (Sugiyono, 2012 : 89)menyebutkan bahwa metode penelitian deskriptif digunakan untuk berupaya memecahkan atau menjawab permasalahan yang sedang dihadapi pada situasi sekarang dilakukan dengan langkah-langkah pengumpulan klasifikasi dan analisis/pengolahan data serta membuat kesimpulan dan laporan dengan tujuan utama untuk penggambaran tentang suatu keadaan secara objektif dalam suatu deskripsi situasi.

Metode deskriptif merupakan metode yang bertujuan untuk mengetahui sifat serta hubungan yang lebih mendalam antara objek dengan cara mengamati aspek-aspek tertentu secara lebih spesifik untuk memperoleh data yang sesuai dengan masalah yang ada dengan tujuan penelitian, dimana penelitian tersebut diolah, di analisis, diproses lebih lanjut dengan dasar teoriteori yang telah dipelajari sehingga dapat ditarik sebuah kesimpulan. Dan 
penelitian ini merupakan penelitian lapangan (field research) yaitu penelitian yang bertujuan untuk mengetahui apakah peranan pengendalian internal atas penjualan, piutang, dan penerimaan kas pada PT. Alfa Scorpii.

\section{HASIL PENELITIAN DAN PEMBAHASAN}

\section{Pengendalian Internal Atas Penjualan Pada PT. Alfa Scorpii}

Pengendalian internal atas penjualan sudah berjalan dengan baik, hal ini terbukti didukung dengan hasil wawancara yang dilakukan kepada pak oscar suheri, karena sudah adanya pemisahan tugas dan wewenang antar karyawan sehingga meminimalisir kesalahan dan kecurangan yang mungkin bisa terjadi diperusahaan. Kaitannya dengan teori pengendalian internal penjualan, Menurut Mulyadi dokumen yang terkait dalam penjualan kredit, yaitu jurnal penjualan untuk mencatat transaksi penjualan, kegiatan yang meliputi analisis, penelaahan dan penelitian yang dilakukan terhadap kebijaksanaan, prosedur, metode, dan pelaksanaan kegiatan penjualan yang sesungguhnya untuk mencapai volume penjualan yang dikehendaki, dengan biaya yang wajar dan dapat menghasilkan laba kotor yang diperlukan untuk mencapai hasil pengembalian yang investasi (return of investmen diharapkan atas). Dapat disimpulkan bahwa hasil penelitian yang diperoleh sudah sesuai dengan teori yang berkaitan karena menganalisis dari prosedur penjualan, pelaksanaan kegiatan yang terpisah antar karyawan, sehingga dapat diorganisir dengan baik maka dari itu tercapainya tujuan perusahaan dalam memperoleh laba sesuai target. Yang menjadi referensi pengendalian internal atas penjualan adalah pada penelitian Lukman (2014) yang memiliki persamaan meneliti pengendalian intern atas penjualan dan penerimaan kas, perbedaannya pada penelitian terdahulu tidak menggunakan variabel piutang, tempat yang diteliti, masalah yang diteliti dan hasil yang didapatkan. Kemudian yang menjadi referensi selanjutnya adalah pada penelitian Wiyani (2016) yang memiliki persamaan meneliti penjualan, akan tetapi perbedaannya terletak pada penelitian terdahulu menganalisis prosedur dan meneliti penjualan kredit saja, subjek penelitian dan hasil yang didapatkan.

\section{Pengendalian Internal Atas Piutang Pada PT. Alfa Scorpii}

Pengendalian internal atas piutang, hal ini terbukti didukung dengan hasil wawancara yang dilakukan kepada ibu andika lubis sudah berjalan baik juga, karena sudah memisahkan bagian-bagian sesuai dengan bidangnya masing-masing, jadi tidak terjadi kebingungan saat melakukan tugas yang diberikan oleh atasan dan perusahaan pun menjadi aman karena dapat mengurangi kecurangan yang bisa ditimbulkan dari karyawan tersebut. Kaitannya dengan teori pengendalian internal piutang, Menurut Mulyadi harus 
memperhatikan organisasi, sistem otorisasi, dan prosedur pencatatan dan praktik yang sehat dalam melakukan aktivitas piutang, salah satu cara yang perusahaan lakukan untuk mengantisipasi kemungkinan piutang tak tertagih, dengan adanya pengendalian piutang ini diharapkan perusahaan dapat meminimalisasi kerugian yang ditimbulkan dari piutang tak tertagih tersebut. Dapat disimpulkan bahwa hasil penelitian yang diperoleh sudah baik, karena sudah dilakukan oleh karyawan yang melakukan tugas nya masing-masing salah satunya dalam proses membuat daftar tagihan hingga melakukan proses penagihan yang sesuai dengan ketentuan perusahaan, maka dapat meminimalisir terjadinya piutang yang tidak tertagih. Yang menjadi referensi pengendalian internal atas piutang adalah pada penelitian Z.Tirayoh (2015) yang memiliki persamaan meneliti pengendalian internal piutang, objek penelitian, akan tetapi perbedaannya pada penelitian terdahulu menggunakan variabel piutang usaha, tempat yang diteliti, dan hasil yang didapatkan.

\section{Pengendalian Internal Atas Penerimaan Kas Pada PT. Alfa Scorpii}

Pengendalian internal atas penerimaan kas, hal ini terbukti didukung dengan hasil wawancara yang dilakukan kepada ibu ani belum dijalankan sesuai prosedur karena karyawan dibagian menginput penerimaan uang tunai kadang masih suka menutupi setoran dari orang lain dikarenakan menunda pencatatan uang tunai sehingga mencuri uang. Seharusnya setiap penerimaan kas diperusahaan itu perlu di koordinir oleh pihak manager uang kas harian setiap hari dengan mendapatkan laporan dari pihak admin, dan setiap uang keluar dari perusahaan setiap hari wajib ada tanda tangan manager, agar pihak admin tidak bisa menyelewengkan uang perusahaan. kaitannya dengan teori pengendalian internal penerimaan kas, Menurut Mulyadi penerimaan kas pada perusahaan berasal dari dua sumber utama yaitu penerimaan kas dari penjualan tunai dan penagihan piutang, ada beberapa prinsip yaitu petugas yang menangani bagian penerimaan kas tidak boleh merangkap sebagai pelaksana pembukuan/pencatatan atas penerimaan kas tersebut, sebaliknya petugas yang menangani pembukuan tidak boleh mengurusi kas, setiap kali penerimaan kas harus segera dicatat, penerimaan kas setiap hari harus disetorkan seluruhnya ke bank, apabila memungkinkan sebaiknya diadakan pemisahan fungsi penerimaan kas dengan fungsi pengeluaran kas. Dapat disimpulkan bahwa hasil penelitian yang diperoleh belum baik dikarenakan tidak sesuai dengan prinsip pengendalian penerimaan kas yang mana ketika ada penerimaan kas tidak segera dicatat menunda dahulu, maka dapat terjadinya kecurangan. Yang menjadi referensi pengendalian internal atas penerimaan kas adalah pada penelitian M. Machtar (2012) yang menjadi persamaan nya terletak pada ketiga variabel yang sama namun memiliki 
perbedaan pada subjek penelitian dan hasil yang didapatkan. Kemudian yang menjadi referensi selanjutnya adalah pada penelitian septiani (2021) yang menjadi persamaan terletak pada objek penelitian dan variabelnya, akan tetapi perbedaannya variabelnya pada penelitian terdahulu menggunakan fungsi, subjek penelitian dan hasil yang didapatkan

Peneliti untuk mengetahui pengendalian internal atas penjualan, piutang dan penerimaan kas memiliki masing-masing prosedur. Prosedur penjualan terdiri atas prosedur penjualan secara tunai dan prosedur penjualan secara kredit, yang sudah tersusun secara urut yang dimulai dari bagian order penjualan kemudian ke bagian gudang, ke bagian kasir, hingga pengiriman. Prosedur piutang yang sudah tersusun juga secara berurut, dan prosedur penerimaan kas yang sudah tersusun secara berurut juga yang dimulai dari pelanggan, ke bagian kasir hingga sampai ke pimpinan. Dari prosedur itulah aset perusahaan akan terlindungi karena sudah terkontrol dengan semestinya. Penjualan produk kendaraan secara tunai maupun kredit sepeda motor Yamaha memiliki beberapa tipe motor seperti Yamaha V-ision, Jupiter Z, New Vega, Mio Sporty, New RX-King, Jupiter M, Scorpio Z, Bison dan sebagainya, penjualan di PT. alfa Scorpii tidak hanya menjual produk sepeda motor tetapi juga ada penjualan jasa servis sepeda motor, yang dilakukan oleh karyawan dibagian otomotif yang melayani para konsumen yang memiliki kendala pada kendaraannya, serta adanya penjualan suku cadang atau sparepart merk yamaha yang asli dijamin oleh yamaha.

Menurut Lukman (2014) dalam mengendalikan intern atas penjualan dan penerimaan kas sebagian besar sama dengan peneliti yang menjadi pembedanya ialah dalam jurnal tersebut tidak mengendalikan piutang dan mengukur terhadap efektifitas perusahaan sedangkan dalam penelitian mengendalikan piutang juga dan tidak mengukur terhadap efektifitas perusahaan. Sehingga hal ini menjadi perbedaan antara peneliti yang terdahulu dengan penelitian ini.

Menurut M. Machdar (2012) dalam menganalisis pengendalian internal oleh M. Machdar menggunakan dalam rangka kegiatan operasi perusahaan dan dilakukan di PT. Listex Prima, sedangkan dalam menganalisis pengendalian internal yang dilakukan oleh peneliti tidak menggunakan dalam rangka kegiatan operasi perusahaan dan dilakukan di PT. Alfa Scorpii. Sehingga hal ini yang menjadi perbedaan antara penelitian yang terdahulu dengan penelitian ini. 


\section{KESIMPULAN}

Berdasarkan hasil penelitian dan pembahasan yang telah dikemukakan oleh peneliti, maka dapat ditarik kesimpulan diantaranya ialah sebagai berikut :

1. PT Alfa Scorpii atau disebut alfa Scorpii dalam guideline ini telah berkecimpung didunia bisnis otomotif selama lebih dari 30 tahun sebagai main dealer sepeda motor merk YAMAHA di 4 provinsi, yakni NAD, sumatera utara, riau daratan, dan riau kepulauan.

2. Pengendalian internal atas penjualan di PT. Alfa Scorpii sudah berjalan dengan baik karena sudah adanya pemisahan tugas dan wewenang antar karyawan sehingga meminimalisir kesalahan dan kecurangan yang mungkin bisa terjadi diperusahaan.

3. Pengendalian internal atas piutang di PT. Alfa Scorpii sudah memisahkan bagian-bagian sesuai dengan bidangnya masing-masing, jadi tidak terjadi kebingungan saat melakukan tugas yang diberikan oleh atasan dan perusahaan pun menjadi aman karena dapat mengurangi kecurangan yang bisa ditimbulkan dari karyawan tersebut.

Pengendalian internal atas penerimaan kas di PT Alfa Scorpii belum dijalankan sesuai prosedur karena karyawan dibagian menginput penerimaan uang tunai kadang masih sering menutupi setoran dari orang lain dikarenakan menunda pencatatan uang tunai sehingga mencuri uang.

\section{DAFTAR PUSTAKA}

Arikunto. (2014 ). Prosedur Penelitian Suatu Pendekatan Praktik. Jakarta : Rineka Cipta.

Effendi , M. (2016). The power of good corporate governance. Jakarta: Salemba Empat.

Hery. (2017). Kajian Riset Akuntansi. Jakarta: PT. Grasindo.

Hery. (2013). Pengendalian Akuntansi dan Manajemen. Jakarta: Kencana Prenadamedia Group.

Hery. (2011). Teori Akuntansi. Cetakan 2. Jakarta: Kencana.

Kasmir. (2012). Analisis Laporan Keuangan . Jakarta: PT. Raja Grafindo Persada.

Kotler. (2016). Marketing Management. Boston: Pearson Education.

Mulyadi. (2012). Akuntansi Biaya. Yogyakarta: UPP STIM YKPN Universitas Gadjah mada.

Mulyadi. (2013). Sistem Akuntansi, Edisi Ketiga, Cetakan Keempat. Jakarta : Salemba Empat.

Reeve, J. M., \& DKK. (2011). Pengantar Akuntansi-Adaptasi Indonesia. Jakarta: Salemba Empat.

Romney. (2014). Sistem Informasi Akuntansi. Jakarta: Salemba Empat. 
Rudianto. (2012). Pengantar Akuntansi Konsep \& Teknik Penyusunan Laporan Keuangan . Jakarta : Erlangga.

Sugiyono. (2012). Memahami Penelitian Kualitatif . Bandung: Alfabeta.

sugiyono. (2015). metode Penelitian Kombinasi (Mix Methods). Bandung : Alfabeta.

Sunyoto, D. (2013). Metodologi Penelitian Akuntansi. Bandung: PT Refika Aditama Anggota Ikapi.

Syamsuddin. (2011). Manajemen Keuangan Perusahaan : Konsep Aplikasi dalam

Perencanaan, Pengawasan, dan Pengambilan Keputusan Edisi Baru 11. Jakarta:

Rajawali Pers .

Warren, C., \& Dkk. (2017). Penghantar Akuntansi 1. Jakarta: Salemba Empat.

Lukman, M. (2014). Analisis Pengendalian Intern Atas Penjualan dan Penerimaan Kas Terhadap Efektifitas Perusahaan Pada PT. Astra Internasional, Tbk - Isuzu Cabang Bogor. Jurnal Ilmiah.

Harmen, R. A, \& Machdar, N. M. (2012). Peranan Pengendalian Intern Atas Penjualan, Piutang dan Penerimaan Kas Dalam Rangka Kegiatan Operasi Perusahaan PT. Listex Prima. Jurnal Manajemen \& Agribisnis. Vol 17 no.2.

Indrijayanti, S,\&Wiyani, N. T. (2016). Analisis Prosedur Pengendalian Intern Penjualan Kredit Pada PT Prima Orbit. Jurnal Mahasiswa Bina Insani. Vol 1 No.1.

Singal, C. R, \& Tirayoh, V. Z. (2015). Analisis Pengendalian Internal Piutang Usaha Pada Developer Grand Kawanua International City. Jurnal EMBA. Vol 3 No.1.

Septiani, W. (2020). Evaluasi Pengendalian Internal Atas Fungsi Penjualan dan Penerimaan Kas Pada PT. Hanang Gema Instrument. Jurnal Ekonomi Bisnis Indonesia. Vol 15 No.1.

Yusuf, P. S, \& Novianto, R. A. (2021). The Role Of Control Of Internal Business Receivables In Supporting The Effectiveness Of Receiving Business Receivables (Case Study At PT X). Turkish Journal Of Computer And Mathematics Education. Vol 12 No.4.

Navalina, I. L. P, DKK. (2021). DesigningAccounting Information Systems for Primary Cash Receipts and Expenditures in Open ERP-based Retail Units (ODOO). Journal Of Social Sciences. Vol 4 No.2.

Setiawan, Samhis. (2020). Pengertian Penjualan - Jenis, Tujuan, Faktor, Pasar, Para Ahli. (Online). Tersedia : https://www.gurupendidikan.co.id/ Pengertian-penjualan/. Html (24 November 2020) 22.05

Hayati, Rina. (2020). Pengertian Subjek Penelitian dan Contohnya. (Online). Tersedia : https://penelitianilmiah.com/subjek-penelitian/. Html (30 November 2020) 23.32 
Hayati, Rina. (2020). Pengertian Objek Penelitian dan Contohnya. (Online). Tersedia : https://penelitianilmiah.com/objek-penelitian/. Html (30 November 2020) 23.53

Rafinska, Kezia. (2020). Return Penjualan dan Return Pembelian Transaksi Jual Beli. (Online). Tersedia : https://www.online-pajak.com/tentang-ppnefaktur/ retur-penjualan-dan-retur-pembelian-dalam-transaksi-jual-beli. Html (11 Desember 2020) 23.28 